\title{
Milling as a Pretreatment Method for Increasing the Reactivity of Natural Zeolites for Use as Supplementary Cementitious Materials
}

Lisa E. Burris ${ }^{1 *}$

lisa.burris@ce.gatech.edu

Maria C. G. Juenger

mjuenger@mail.utexas.edu

Department of Civil, Architectural and Environmental Engineering, University of

${ }^{1}$ Present address: School of Civil and Environmental Engineering, Georgia Institute of Technology, 790 Atlantic Dr, Atlanta, GA 30332. 


\section{ABSTRACT}

27 This work examined the effects of milling using a gravity ball mill on the

28 reactivity of natural zeolites used as supplementary cementitious materials (SCMs). Six

29 different particle size distributions of zeolites, created by milling the as-received zeolite

30 in a ball mill for a specified amount of time, were characterized using x-ray fluorescence,

31 quantitative $\mathrm{x}$-ray diffraction, particle size analysis, pore size distribution and surface

32 area analysis. Following material characterization, the pozzolanic reactivity of the

33 zeolites was determined by measuring the quantity of calcium hydroxide in paste after 28

34 or 90 days and by tracking the compressive strength of zeolite-cement mortars. Results

35 showed that a critical milling time exists, corresponding to a $\mathrm{d}_{50}$ of $7-9 \mu \mathrm{m}$, after which

36 reductions in particle size can no longer be achieved and zeolite performance can no

37 longer be improved through ball milling.

39 Keywords: zeolite, particle size, milling, pozzolanic reactivity, supplementary

40 cementitious materials, clinoptilolite

\section{INTRODUCTION}

43 Milling, the process of reducing a material's particle size, is a common process in

44 the manufacture of cement and has also been used to prepare other materials, such as

45 ground granulated blast furnace slag, for use as supplementary cementitious materials

46 (SCMs) [1-3]. Many studies have shown that milling can improve the performance of

47 SCMs [2-6], therefore it is hypothesized that milling will also be successful in improving

48 the performance of zeolites as SCMs. Several studies have explored the idea of increasing

49 zeolite reactivity through milling. However, these studies primarily employed high- 
50 energy ball mills operating at speeds in excess of $500 \mathrm{rpm}$ [7-10], conditions that are not

51 feasible for use with the large quantities used in the construction industry. Large-scale

52 milling operations in the construction industry typically consist of large rotary ball mills

53 operating at relatively slow rotational speeds $[11,12]$. This work explores whether

54 conditions similar to those found in industrial cement mills can generate improvements in

55 zeolite performance similar to those seen with the use of high-energy planetary mills.

56 The influence of particle size on the performance of zeolites used as SCMs has

57 not been comprehensively characterized, although several studies' findings point towards

58 increased reactivity of zeolites after a reduction in particle size $[8,9,13-16]$. Charkhi et al.

59 [8] noted that reduction of particle size increases the quantity of external surface area

60 available for interaction and results in shorter diffusion path lengths for sorption

61 applications and also enhancing selectivity. Snellings et al. [16] showed that in paste

62 mixtures of clinoptilolite zeolites and calcium hydroxide in a 1:1 ratio, smaller grain size

63 and higher external surface area increased both the early heat evolution and the rate of

64 heat release during the pozzolanic reaction. In addition, in the zeolite-calcium hydroxide

65 pastes, more calcium hydroxide was consumed by the finer-zeolite mixtures when tested

66 at 6,24 , and 72 hours. Similarly, using $20 \mathrm{~mm}$ cubes made of a hydrated clinoptilolite

67 zeolite and calcium hydroxide, Ortega et al. [15] demonstrated that unconfined

68 compressive strength and zeolite particle size are almost inversely linearly related, with

69 lower particle sizes yielding higher compressive strengths.

70 Interestingly, the researchers that have investigated the effect of zeolite milling

71 have found that milling can not only decrease zeolite particle size, but that long milling

72 time and high rotational speed result in a reduction of crystallinity and increase in the 
73 quantity of amorphous material $[8,9,13,17,18]$. Kosanovic et al. [13] milled a $1 \mathrm{~g}$ zeolite

74 sample using $10 \mathrm{~mm}$ Wolfram carbide balls in a planetary ball mill operated at $3000 \mathrm{rpm}$.

75 During the first $15-20$ minutes of milling they found that $75 \%$ of the crystalline phase

76 was converted to amorphous material in addition to reduced particle sizes [13]. Zielinski

77 et al. [9] saw similar results after milling six types of artificially-synthesized zeolites in a

78 high-energy ball mill using a set of three $9.5 \mathrm{~mm}$ diameter steel balls and a speed of 1010

$79 \mathrm{rpm}$. The crystallinity of all six types of zeolite was significantly reduced after only ten

80 minutes of milling and eliminated in nearly all of the samples by 60 minutes. Charkhi et

81 al. [8] also saw nearly complete elimination of clinoptilolite zeolite crystallinity after

82 milling for only 20 minutes at $600 \mathrm{rpm}$ using $20 \mathrm{~mm}$ zirconium oxide balls and a high-

83 energy planetary ball mill. Similarly, Xie and Kaliaguine [10] found that KNaX zeolite (a

84 type of synthetic zeolite created from a kaolin precursor) milled at $1010 \mathrm{rpm}$ became

85 amorphous after 120 minutes of milling. The de-crystallization of zeolite crystals with

86 milling was suggested by several researchers to occur as a result of breakage of the Si-O-

87 Si and Si-O-Al bonds on the external surface of the zeolite leading to structural collapse $88[8,13]$.

89 In addition to reductions in particle size and crystallinity, other researchers

90 observed changes in the zeolite pore structure and surface area after milling. Xie and

91 Kaliaguine [10] found that milling their $\mathrm{KNaX}$ zeolite at $1010 \mathrm{rpm}$ progressively reduced

92 the surface area and micropore volume with increasing milling time. The work of

93 Zielinski et al. [9] suggested that ball milling initially opened macropores. However,

94 additional milling time caused these pores to gradually disappear. They linked the rate of 
95 surface area loss resulting from the destruction of the macropores to the $\mathrm{SiO}_{2} / \mathrm{AlO}_{3}$

96 content of the zeolites, with high silica materials decomposing more slowly.

97 The results of studies examining the effects of ball milling on zeolite properties

98 suggest that milling can increase zeolite amorphous content, decrease particle size, and

99 increase accessible porosity. Such changes should produce increased pozzolanic

100 reactivity of the zeolite and improve the performance of zeolite-cement mixtures using

101 milled zeolites [19-22]. However none of the studies in the literature examining milled

102 zeolites actually tested milled zeolites in cementitious systems. Therefore, this study

103 examined the effects of ball milling on zeolite properties, including external surface area,

104 particle size, and crystallinity, and investigated the correlation between these properties

105 and zeolite-cement mixture performance using milling techniques closer to those

106 currently in use by the construction industry.

107

1083 MATERIALS AND EXPERIMENTAL METHODS

$109 \quad 3.1 \quad$ Materials

110 Clinoptilolite zeolite, mined from Tilden, Texas, was used throughout this study.

111 The zeolite was classified by the supplier as \#30 $(0.595 \mathrm{~mm})$ mesh size, and was not

112 treated or washed before delivery. The chemical composition, determined using x-ray

113 fluorescence (XRF) is shown in Table 1.

114 An ASTM C150 [23] Type I/II Texas Lehigh cement, referred to hereafter as

115 'ordinary portland cement' (OPC), was used for all pastes and mortars in this work. The

116 chemical and physical properties of the cement are shown in Table 1. A quartz filler (Old

117 Hickory, Clay World) was used throughout this work to help differentiate between 
118 improvements due to filler effect and those occurring as a result of the pozzolanic

119 reaction. The particle size distributions of the OPC and quartz filler are shown in Figure

120 1. The particle size of the quartz filler was similar to the average particle size of the

121 milled zeolite samples investigated in this study. An ASTM C109 [24] graded Ottawa

122 sand, certified to meet the ASTM C778 [25] standard, was used for all mortars in this 123 work.

\section{$125 \quad 3.2 \quad$ Milling}

126 Although several literature studies investigated the effect of milling on zeolites

127 milled in high energy planetary mills, a simple rotational mill was chosen to mimic the

128 conditions present in mills currently used to grind cement clinker or other SCMs such as

129 metakaolin, since this type of milling would be more feasible to industrially implement.

130 A low powder load of $30 \%$, corresponding to a formal interstitial filling of the void

131 spaces of the ball bed, was chosen to mimic the conditions present in industrial cement

132 grinding mills [11]. Prior to milling, samples were dried at $105^{\circ} \mathrm{C}$ for 12 hours in a

133 ceramic crucible. The mill was operated at $85 \mathrm{rpm}$, or $75 \%$ of the critical speed, similar to

134 industrial cement ball mills. The zeolite was then milled for 1, 2, 4, 6, or 8 hours. In

135 preliminary testing it was noticed that samples ground for longer than 2 hours became

136 caked against the sides of the mill. This was believed to be a result of moisture released

137 from the zeolite as particle size was reduced, so samples ground for longer than 2 hours

138 were stopped at 2 hours of milling and dried for an additional 8 hours at $105^{\circ} \mathrm{C}$ to remove

139 excess moisture from the system, then returned to the ball mill to continue milling. 


\section{$141 \quad 3.3 \quad$ Zeolite Physical and Chemical Characterization Testing}

142 The zeolite physical and chemical properties were characterized in order to

143 determine the changes resulting from milling and which of these factors contributed to

144 changes in zeolite reactivity in cementitious systems. Characterization testing tracked

145 changes in particle size, surface area and crystalline phases present in the zeolites.

146 X-ray diffraction (XRD) was used to determine what phases were present in each

147 sample and to gauge the effectiveness of reducing crystallinity by milling. XRD samples

148 were prepared by grinding the treated sample to a powder passing the No. $325(44 \mu \mathrm{m})$

149 sieve using an agate mortar. Each specimen was then pressed into plastic XRD sample

150 holders using a glass plate such that the plane of the specimen surface was even with the

151 edge of the sample holder in order to create a specimen face in the focusing circle of the

152 powder diffractometer [26]. X-ray diffraction scans were performed using a Siemens

153 D500 x-ray diffractometer, using a copper x-ray source producing Ni-filtered $\mathrm{CuK} \alpha$

154 radiation. The diffractometer was operated at $40 \mathrm{kV}$ and $30 \mathrm{~mA}$ with scans taken from 5-

$15570^{\circ} 2 \theta$ with a step size of $0.2^{\circ} 2 \theta$ and a 2 second dwell time. The diffractometer was

156 configured with $4^{\circ}$ soller slits and $1^{\circ}$ anti-scatter slits on both the beam and detector

157 sides, a $1^{\circ}$ divergence slit on the beam side and a $0.15 \mathrm{~mm}$ receiving slit and $0.6 \mathrm{~mm}$

158 detector slit on the detector side. $\mathrm{Cu} \mathrm{K}-\beta$ radiation was removed before reaching the

159 detector by a graphite monochromator. Crystalline phases present in each zeolite were

160 determined using files from the inorganic crystal structure database [27] and Jade MDI

161 software package [28]. Relative crystallinity was qualitatively gauged according to the

162 reduction of the peak heights of each phase compared to other phases present in the

163 material. In general, lower peak heights correlate with lower sample crystalline content 164 [29]. 
166 nitrogen sorption using a Micromeretics ASAP 2020 Surface Area and Porosimetry

167 Analyzer. Prior to measurement, zeolite samples and the sample tubes were individually

168 weighed to microgram precision. The raw zeolite samples were then degassed for 12

169 hours at $100^{\circ} \mathrm{C}$ and a pressure of $500 \mu \mathrm{mHg}$ or less. Pretreated samples were degassed for

1706 hours at $300^{\circ} \mathrm{C}$ and a pressure of $500 \mu \mathrm{mHg}$ or less. Samples were heated individually

171 during degassing using a heating mantle with a Type K thermocouple controlled by the

172 nitrogen adsorption testing software program. After degassing, samples were reweighed,

173 and this value was used as the sample mass for analysis. Nitrogen adsorption was tracked

174 using high purity nitrogen as the adsorbate with liquid nitrogen used as the coolant. All

175 the values of the adsorbed volume reported at the isotherm are equal to the equivalent gas

176 volume in standard pressure and temperature $(273 \mathrm{~K}, 1 \mathrm{~atm})$. The surface area and pore

177 size distribution were calculated from $\mathrm{N}_{2}$ adsorption-desorption isotherms recorded at the

178 temperature of liquid nitrogen $(77 \mathrm{~K})$. Surface area was determined using the BET model

179 [30] and pore size distribution with the BJH model [31]. For this study, nitrogen-

180 available internal surface area (hereafter, internal surface area) of each sample was

181 calculated as the difference between the total nitrogen-available surface area determined

182 by BET and the external surface area calculated using a t-plot. Due to the large internal

183 surface area inherent in the zeolite crystal structure, surface area and particle size were

184 assumed to be independent of each other for the purposes of this work.

185 Changes to material particle sizes were tracked in order to determine the effect of

186 pretreatments on the particle size distribution of the zeolite, as well as the role particle

187 size plays in the generation of zeolite-cement system properties. Particle size distributions 
188 of the zeolites were measured before and after milling using a Malvern 2000 Laser

189 Particle Size Analyzer. Enough sample was added to $1 \mathrm{~L}$ of distilled water to generate 5-

$19015 \%$ obscuration and was ultrasonicated for 60 seconds in order to reduce particle

191 agglomeration. The instrument default optical parameters were used for all materials,

192 with a refractive index of 1.5026 and 1.33 used for the zeolites and water, respectively.

193 Measurements were taken in triplicate over 10 seconds using both a HeNe red gas laser

194 and a LED blue light in a reverse Fourier convergent beam lens arrangement. The laser

195 light scattering measurements were analyzed by the Malvern software using Mie

196 Scattering Theory and Fraunhofer Diffraction Theory in order to generate an average

197 particle size distribution data for each sample.

\section{$198 \quad 3.4 \quad$ Zeolite Reactivity Testing}

199 In this study two methods were used to track changes to zeolite pozzolanic 200 reactivity after milling: 1) measurement of calcium hydroxide content of hydrated

201 zeolite-cement pastes and 2) compressive strength developement in zeolite-cement 202 mortars. All pastes and mortar mixtures used a $20 \%$ replacement by mass of cement with 203 zeolite.

204 The calcium hydroxide content of hydrated zeolite-cement pastes was determined 205 for pastes using unmilled zeolite and zeolite milled for $0,2,4,6$ or 8 hours. The calcium 206 hydroxide (also called portlandite) content of hydrated zeolite-cement pastes was 207 determined for pastes using unmilled and milled zeolites, with a water to cementitious 208 materials ratio $(\mathrm{w} / \mathrm{cm})$ of 0.4 , and a $20 \%$ replacement by mass of cement with zeolite.

209 Before the addition of water, the cement and zeolite were mixed together by hand for 30

210 seconds. The cement, zeolite, and water samples were then mixed by hand for two 
211 minutes and each $14 \mathrm{~g}$ sample was sealed in an individual plastic cup and cured at $23^{\circ} \mathrm{C}$.

212 At 28 or 90 days after mixing, the sample was removed from the cup, the edges of each

213 sample were removed, the remaining sample mass was recorded and the sample was

214 crushed to pass the No. $8(2.36 \mathrm{~mm})$ sieve. The sample was dried under vacuum for seven

215 days to stop hydration. After seven days the sample was reweighed to determine the mass

216 loss of water in the system and then ground to pass the No. $100(149 \mu \mathrm{m})$ sieve. Each

217 sample was then heated to $1000^{\circ} \mathrm{C}$ at a temperature ramp rate of $20^{\circ} \mathrm{C} / \mathrm{min}$ in a nitrogen

218 environment in a Mettler Toledo Thermogravimetric Analyzer.

219 The amount of calcium hydroxide present in the sample was calculated from the

220 amount of mass lost from approximately $450^{\circ} \mathrm{C}$ to $550^{\circ} \mathrm{C}$, which corresponds to the

221 dehydration of calcium hydroxide $\left(\mathrm{Ca}(\mathrm{OH})_{2}\right)$ according to Equation 1 [32]:

$$
\mathrm{Ca}(\mathrm{OH})_{2} \leftrightarrow \mathrm{CaO}+\mathrm{H}_{2} \mathrm{O}
$$

223 It was assumed that one mole of calcium hydroxide was present for each mole of $\mathrm{H}_{2} \mathrm{O}$ 224 lost in this range. The dehydration temperatures used were tailored to each specific 225 sample using the inflection points on the differential thermogravimetric analysis curves to 226 determine the start and end of dehydration for each sample. The quantity of calcium 227 hydroxide present in the paste was normalized by the anhydrous cement content of the 228 paste.

229 The influence of milling on compressive strength was tested on mortars of cement 230 and either unmilled zeolite or zeolites milled for 0,2 or 8 hours. All zeolite-cement 231 mortars used a $20 \%$ substitution by mass of zeolite for cement. Mortars using a $20 \%$ 232 substitution by mass of cement with a finely ground quartz were used to understand 233 whether differences between zeolite-containing mortars and cement-only control mortars 
234 were occurring due to a filler effect or from contributions of the zeolite [33]. $50 \mathrm{~mm}$ (2-

235 in.) mortar cubes, mixed in accordance with ASTM C305 [34], were cast at a w/cm of

2360.51 , in order to provide adequate workability for the high water demand zeolite

237 mixtures. The cubes were removed from the molds after 24 hours and stored in limewater

238 at $23^{\circ} \mathrm{C}$ until tested. Compressive strengths were obtained $1,3,7,28$ and 90 days after

239 mixing following the procedures of ASTM C109 [24].

\section{$241 \quad 3.5 \quad$ Testing to Determine the Effects of Zeolite on Cement Hydration}

242 Isothermal calorimetry was used to examine the effects of the milled zeolites on

243 cement hydration kinetics. Testing was done on cement pastes with $0 \%$ or $20 \%$ zeolite

244 mass replacement of cement for zeolite milled for $0,2,4,6$, or 8 hours. Heat evolution

245 was tracked per gram of cement in a TAM AIR (Thermometric) calorimeter for $10 \mathrm{~g}$ paste

246 samples prepared with a w/cm of 0.4 , and a $20 \%$ mass replacement of cement with

247 zeolite. Samples were hand-mixed for two minutes and placed into vials according to

248 ASTM C1679 [35]. Heat evolution was tracked for 72 hours.

249 Several parameters were investigated using isothermal calorimetry in order to

250 understand how the incorporation of unmilled or milled zeolites affected cement

251 hydration. These parameters include: 1) the slope of the rate of heat evolution versus time

252 curve during the acceleration period, referred to in this work as the rate of reaction in the

253 acceleration period; 2) the time required for the mixture to enter the acceleration period

254 (i.e. the length of the induction period); 3) the time required for the mixture to reach its

255 peak rate of heat release (for the presumed alite peak); 4) the magnitude of the rate of

256 heat evolution at the peak; and 5) the cumulative heat released over 72 hours. In this 
257 study, since the acceleration period was not completely linear, the slope of the 258 acceleration period was standardized by using the slope at the time halfway between the 259 time at which the acceleration period began and the time the maximum rate of heat

260 evolution occurred. The time of the start of the acceleration period was determined for all

261 mixtures in this study as the point at which the minimum rate of heat evolution occurred

262 following the initial peak. The time of the maximum rate of heat evolution was

263 determined for all mixtures in this study as the time to the first maximum occurring after

264 the start of the acceleration period. In cases where the alite and aluminate peaks

265 overlapped and the maximum rate of heat evolution for the alite peak could not be

266 definitively determined, the time the peak occurred was visually estimated. The

267 cumulative heat produced was calculated for each mixture using the heat release

268 measured every three minutes by isothermal calorimetry and applying the trapezoidal

269 rule. If milling improves zeolite interactions with cement hydration, increases in the rate

270 of reaction during the acceleration period [36-38], decreases in the time to the start of the

271 acceleration period and time to the maximum rate of heat release [37], an increased

272 maximum rate of heat release [37] and greater cumulative heat evolved than for a

273 comparable quartz-cement paste can be expected [39]. 


\section{RESULTS}

\section{$276 \quad 4.1 \quad$ Physical and Chemical Characterization Testing Results}

The crystalline phases present in the zeolite before and after milling are shown in

278 Figure 2. Even after 8 hours of milling, crystalline phases in the zeolite appear 279 unchanged.

280 Zeolite particle size distributions before and after milling are shown in Table 2 281 and Figure 3. Particle sizes were reduced progressively over 8 hours of milling with the 282 most significant reduction taking place in the first 4 hours. From Figure 3 it can be seen 283 that milling completely eliminated the coarsest fraction of the original zeolite material $284(>500 \mu \mathrm{m})$ and increased the proportion of material in the $2 \mathrm{~nm}$ and $20 \mathrm{~nm}$ diameter size 285 fractions. Although particle sizes continued to decline slightly from 4 to 8 hours of 286 milling, overall the particle size distribution stabilized after 4 hours of milling, with only

287 slight increases in the volume of fines present in the system after 4 hours of milling.

288 The effect of milling on the nitrogen-accessible surface area of the zeolite is 289 shown in Figure 4 and the materials' pore size distributions are shown in Figure 5. It is 290 evident from Figure 4 that the surface area of the material is inversely correlated with 291 particle size, as it trends upward until 2 hours of milling, at which time there are no

292 further increases in surface area. Figure 5 confirms this hypothesis, as milling had little 293 effect on the pore size distribution of the material.

\section{$295 \quad 4.2 \quad$ Zeolite Reactivity Characterization Results}

296 The pozzolanic reaction occurs when the silica present in a supplementary 297 cementitious material (i.e. a pozzolan, and in this case, a zeolite) reacts with calcium 
298 hydroxide, one of the primary products of cement hydration, to form additional C-S-H.

299 Therefore, differences between the amount of calcium hydroxide present in the paste of a

300 SCM-cement paste and an OPC cement paste can give quantifiable information on the

301 ability of SCMs to react pozzolanically [39-41]. The reaction of calcium hydroxide to

302 form C-S-H can also result in decreases in porosity and corresponding increases in

303 strength [41]. Therefore, in this study, two methods were used to track changes to zeolite

304 pozzolanic reactivity after milling: 1) measurement of calcium hydroxide content of

305 hydrated zeolite-cement pastes and 2) compressive strength development in cement-

306 zeolite mortars. The calcium hydroxide contents of hydrated pastes containing unmilled

307 and milled zeolite are shown in Figure 6. The pastes containing unmilled zeolite showed

308 evidence of the pozzolanic reaction, with the unmilled zeolite-cement pastes having

309 lower calcium hydroxide contents than both the sample using inert quartz filler and the

310 cement-only paste. Antoni et al. [42] showed that a quartz filler increased the amount of

311 calcium hydroxide produced compared to a cement-only paste because it allows more

312 space for hydration product growth. The same effect is shown in Figure 6 for the quartz-

313 cement paste sample. The reduction in calcium hydroxide content compared to the quartz

314 filler sample is due to the pozzolanic reaction of the added zeolite. The greater increase in

315 calcium hydroxide content from 28 to 90 days in the zeolite-cement pastes compared to

316 the cement-only paste indicates that the pozzolanic contribution of the zeolite has either

317 been completed, or at least considerably slowed, prior to 90 days.

318 As far as the relationship between mill time and pozzolanicity of the zeolite is

319 concerned, milling the zeolite for 1 hour did not change the zeolite pozzolanicity

320 relative to the unmilled zeolite. The zeolite milled for 1 hour showed the same 
321 magnitude of reduction of calcium hydroxide as the unmilled sample. Milling times

322 greater than 1 hour were successful in improving the calcium hydroxide consumption

323 of the zeolite, with calcium hydroxide contents of the 28-day samples lower than for the

324 paste with unmilled zeolite. Milling for 4 hours further increased the calcium hydroxide

325 consumption, however further improvements were not seen with mill times greater than

3264 hours, as expected since the particle size was not changed with extended milling.

327 The effect of milling on the compressive strengths of the zeolite-cement mortars

328 is shown in Figure 7. Milling the zeolite increased the compressive strengths of the

329 mortars at all ages compared to the unmilled zeolite mortar. However, the zeolite milled

330 for 8 hours generated significantly more compressive strength in a mortar than the zeolite

331 milled for 2 hours. Strengths of the zeolite-cement mortars were initially lower than or

332 equal to strengths generated by mortars containing a similar replacement level of a quartz

333 filler, however the strengths of the unmilled zeolite-cement mortars exceeded that of the

334 quartz filler mortars after 28 days, while the strengths of the milled zeolite-cement

335 mortars exceeded the quartz filler mortars after only 7 days.

$337 \quad 4.3 \quad$ Influence of Milled Zeolites on Cement Hydration Testing Results

338 The effects of milled zeolite on cement hydration kinetics are shown in Figure 8 to

339 11. Both the unmilled and milled zeolites decreased the time to the start of the

340 acceleration period and also decreased the time to the maximum rate of heat release

341 compared to the cement-only paste (Figure 9), likely through contribution of C-S-H

342 nucleation sites. It is apparent, however, from Figure 11 that the zeolites do not behave at

343 early ages merely as inert fillers, as their influence on the rate of and quantity of heat 
344 released is significantly greater than the quartz filler-cement paste regardless of the

345 particle size of the zeolite. Other researchers have suggested that this effect is due to

346 increased adsorption of $\mathrm{Ca}^{2+}$ on zeolite surfaces, resulting in more rapid dissolution of

$347 \mathrm{C}_{3} \mathrm{~S}$ and growth of C-S-H [43].

348 Despite increasing the rate of nucleation of cement hydration products, overall the

349 unmilled zeolite may have hindered the total extent of cement hydration, evidenced by

350 the lower maximum rate of heat released by the cement compared to the cement-only

351 paste (Figure 10), and lower rate of reaction in the acceleration period (Table 3). In

352 contrast, the pastes using milled zeolites generated greater rates of heat release per gram

353 of cement than the cement-only paste, the quartz filler paste and the unmilled zeolite-

354 cement paste. Longer milling times correlated with greater reductions in times to the end

355 of the induction period and the time to peak rate of heat release. Milled zeolites also

356 increased the rate of reaction during the acceleration period compared to the cement-only,

357 quartz and unmilled zeolite-cement pastes (Table 3). Similar to the results seen with the

358 calcium hydroxide testing, initial milling for one and two hours resulted in increases in

359 the rate of reaction during the acceleration period. Additional milling, for 4 hours, further

360 increased the slope of the acceleration period but the rates of reaction during the

361 acceleration period of the 4, 6 and 8 hour milled zeolite-cement pastes were equivalent,

362 as expected from their similar particle size distributions. Time of milling did not seem to

363 make a significant difference in the magnitude of the maximum rate of heat release,

364 shown in Figure 8 and Figure 10, as all milled samples had similar maximum rates.

365 Similarly, Figure 11 shows that, except for the paste using zeolite milled for 8 hours, all

366 milled zeolite-cement pastes produced similar amounts of heat over 72 hours. 


\section{DISCUSSION OF THE EFFECTS OF MILLING ON ZEOLITE} 369 POZZOLANIC REACTIVITY

370 The goal of the ball milling was to improve the properties of the zeolite to allow it

371 to react faster or more completely as a pozzolan, resulting in improved performance in

372 cementitious systems. It was hypothesized that milling would result in reduced particle

373 sizes, increased porosity, and a loss of zeolite crystallinity, creating a more reactive

374 material. The literature suggests that milling substantially reduces zeolite crystallinity

375 with very short durations of milling $[8,9,11,13,17,18]$. However, nearly all of the studies

376 of milled zeolites to date employed planetary ball mills capable of much greater forces

377 than cylindrical ball mills with only a single axis of rotation, such as the mill used in this

378 work and by the cement industry. It is evident from the XRD results shown in Figure 2

379 that the forces imposed on the zeolites in a horizontal rotary ball mill were not high

380 enough to cause a reduction in zeolite crystallinity as in the studies using high energy

381 planetary ball mills.

382 Although milling did not reduce the zeolite crystallinity, it did significantly

383 reduce particle size, leading to increased surface area of the zeolite, as shown in Table 2

384 and Figure 3 and 4. Contrary to previous work that showed that milling increased

385 porosity through the creation of macropores [9], very little change occurred in the pore

386 sizes of the material, shown in Figure 5, and it can be assumed that the increases in

387 surface area in this work occurred only as a result of the reductions in particle size.

388 Performance tests on the milled zeolite showed that the pozzolanicity of the 389 zeolite was increased by milling, with milling for four hours corresponding to an average 390 particle size $\left(\mathrm{d}_{50}\right)$ of $9 \mu \mathrm{m}$ or less, resulting in the greatest gains in reactivity. Shown in 
391 Figure 6, zeolite milled for 2 hours or more reduced paste calcium hydroxide content

392 relative to unmilled zeolite. However, milling for greater than 4 hours generated no

393 additional calcium hydroxide reduction. This is as expected, as pastes using the zeolites

394 milled for 4, 6 and 8 hours had similar particle size distributions. In addition to the effect

395 from reduced particle sizes, surface area increases were also found to correlate with

396 decreased calcium hydroxide content of the zeolite-cement pastes. However, as increases

397 in surface area were deemed to occur as a result of reductions in particle size, surface

398 area is not believed to itself be the primary driver of calcium hydroxide content

399 reductions.

400 Evidence of increased pozzolanic reactivity with milling was also shown in the

401 increased compressive strengths of the zeolite-cement mortars. Milled zeolite-cement

402 mortars, shown in Figure 7, yielded significant increases in compressive strengths

403 compared to the unmilled zeolite, as early as 7 days after casting. Similar to the calcium

404 hydroxide testing results, milling for 8 hours did not increase the long term pozzolanic

405 reactivity of the zeolite (as demonstrated by compressive strength) compared to milling

406 for 2 hours, as the 90 day compressive strengths of the mortars containing zeolite milled

407 for 2 or 8 hours were not significantly different. Therefore, particle size seems to play a

408 large role in determining the extent of the pozzolanic reactivity of the milled zeolites.

409 However, particle size and filler effects [42] do not entirely explain zeolite

410 performance as increased milling time did increase the rate of strength development

411 despite the similar particle size distributions of the two samples. Other researchers have

412 concluded that milling can result in breakage of the surface Si-O-Si and Si-O-Al bonds of

413 the zeolite structure $[8,13]$ and this may have played a role in increasing the initial 
414 strength development rate of the zeolite-cement mortars. Longer milling times may have

415 generated greater quantities of broken Si-O and Al-O bonds, enabling the zeolite crystal

416 structure to more easily dissolve and react than with unmilled zeolites and zeolites milled

417 for shorter times which may lack, or have fewer, broken chemical bonds. However, 418 testing the surface characteristics of the zeolites after milling is beyond the scope of the 419 work presented here.

420 In addition to increased pozzolanic reactivity, milled zeolites also contributed an 421 accelerating effect to cement hydration reactions, decreasing both the time to the start of

422 the acceleration period as well as the time of the maximum alite reaction peak, shown in

423 Figures 8 to 10 . These times decreased corresponding to the particle size, with the largest

424 reductions in time seen in the 8 hour milled zeolite. The rates of nucleation and growth, 425 expressed by the slope of the acceleration period and peak rate of heat release values 426 shown in Table 3 and Figure 10, were also increased for all milled zeolites relative to 427 both the cement-only, quartz filler and the unmilled zeolite-cement pastes. Both of these 428 effects are similar to effects seen in the literature with the use of very fine inert quartz 429 fillers [44,45], finer than the one used in this study. However, the length of the hydration 430 reactions during the deceleration period was much shorter for the milled-zeolite pastes 431 compared to the quartz filler-paste. This may indicate that the zeolite particles initially act 432 as nucleating agents, speeding up the timing and rate of reactions, but are not contributing 433 to the dilution effect often seen with fillers which tend to extend the magnitude of 434 hydration during the first 72 hours [39]. 


\section{CONCLUSIONS}

436 Natural zeolite was milled using a ball mill in order to mimic a pretreatment that

437 could be implemented in the field using existing industrial SCM and cement clinker ball

438 mills $[11,52]$. Zeolite was milled for 1, 2, 4, 6, or 8 hours and characterized to determine

439 the changes with ball milling to zeolite crystallinity, particle size, surface area, and

440 porosity. Performance was determined by measuring the calcium consumption in a

441 calcium hydroxide solution, tracking reductions in calcium hydroxide in zeolite-cement

442 pastes due to the pozzolanic reaction, and testing the compressive strengths of zeolite-

443 cement mortars. The effect of milling on early age cement hydration was also

444 investigated.

445 Ball milling of zeolites significantly improved the performance of the zeolite used

446 in cementitious mixtures, increasing the pozzolanic reactivity of the zeolites as well as

447 increasing compressive strengths of mortars containing milled zeolites. Milled zeolites

448 also accelerated cement hydration reactions, seen in isothermal calorimetry, and

449 increased the maximum rate of heat release of the milled zeolite-cement mixtures.

450 Milling zeolites for four hours or longer, corresponding to an average particle size $\left(\mathrm{d}_{50}\right)$

451 of $9 \mu \mathrm{m}$ or less, yielded the greatest gains in reactivity. These improvements were

452 primarily due to decreased particle sizes with milling, but undetected chemical changes to

453 the zeolites with increased mill times may have also contributed to the enhanced 454 performance seen in ball milled zeolite-cement mixtures.

\section{ACKNOWLEDGEMENTS}

456 This work was supported by the National Science Foundation (Project No. CMMI

457 1030972) and the Texas Department of Transportation (Project No. 0-6717). Any 
458 opinions, findings, and conclusions expressed in this document are those of the authors

459 and do not necessarily reflect those of the National Science Foundation or the Texas

460 Department of Transportation. The authors would like to acknowledge Dr. Lynn Katz for

461 her help, advice, and use of her equipment, as well as Maria Lacson, for her help

462 conducting some of this study's experimental work.

\section{$463 \quad 8$ REFERENCES}

464 [1] Snellings R, Mertens G, Elsen J. Supplementary Cementitious Materials. Rev

465 Mineral Geochemistry 2012;74:211-78. doi:10.2138/rmg.2012.74.6.

466 [2] Wan H, Shui Z, Lin Z. Analysis of geometric characteristics of GGBS particles and their influences on cement properties. Cem Concr Res 2004;34:133-7. doi:10.1016/S0008-8846(03)00252-7.

\section{[3] Kumar S, Kumar R, Bandopadhyay a., Alex TC, Ravi Kumar B, Das SK, et al.} Mechanical activation of granulated blast furnace slag and its effect on the properties and structure of portland slag cement. Cem Concr Compos 2008;30:679-85. doi:10.1016/j.cemconcomp.2008.05.005.

[4] Paya J, Monzo J, Borrachero MV, Peris E, Gonzalez-Lopez E. Mechanical treatments of fly ashes. Part III: Studies on strength development of ground fly ashes (GFA) - Cement mortars. Cem Concr Res 1997;27:1365-77.

[5] Lawrence P, Cyr M, Ringot E. Mineral admixtures in mortars effect of type, amount and fineness of fine constituents on compressive strength. Cem Concr Res 2005;35:1092-105. doi:10.1016/j.cemconres.2004.07.004.

[6] Vizcayno C, de Gutiérrez RM, Castello R, Rodriguez E, Guerrero CE. Pozzolan obtained by mechanochemical and thermal treatments of kaolin. Appl Clay Sci 2010;49:405-13. doi:10.1016/j.clay.2009.09.008.

[7] Kosanovic C, Bronic J, Cizmek A, Subotic B, Smit I, Stubicar M, et al. Mechanochemistry of zeolites : Part 3 . Amorphization of zeolite ZSM- 5 by ball milling. Zeolites 1995;15:51-7.

[8] Charkhi A, Kazemian H, Kazemeini M. Optimized experimental design for natural clinoptilolite zeolite ball milling to produce nano powders. Powder Technol 2010;203:389-96. doi:10.1016/j.powtec.2010.05.034. 
[9] Zielinski P a., Van Neste a., Akolekar DB, Kaliaguine S. Effect of high-energy ball milling on the structural stability, surface and catalytic properties of small-, medium- and large-pore zeolites. Microporous Mater 1995;5:123-33. doi:10.1016/0927-6513(95)00050-J.

[10] Xie J, Kaliaguine S. Zeolite ball milling as a means of enhancing the selectivity for base catalyzed reactions. Appl Catal A Gen 1997;148:415-23. doi:10.1016/S0926860X(96)00234-7.

[11] Ene G. The Grinding Charge of Rotary Mills. Ann "Dunarea Jos" Univ Galati 2007:35-41.

[12] Cleary PW. Ball motion, axial segregation and power consumption in a full scale two chamber cement mill. Miner Eng 2009;22:809-20. doi:10.1016/j.mineng.2009.02.005.

[13] Kosanovic C, Bronic J, Cizmek A, Subotic B, Smit I, Stubicar M, et al. Mechanochemistry of zeolites: Part 2. Change in particulate properties of zeolites during ball milling. Zeolites 1995;15:247-52.

[14] Kosanovic C, Subotic B, Smit I, Cizmek A, Stubicar M, Tonejc A. Study of structural transformations in potassium-exchanged zeolite A induced by thermal and mechanochemical treatments. J Mater Sci 1997;32:73-8.

[15] Ortega EA, Cheeseman C, Knight J, Loizidou M. Properties of alkali-activated clinoptilolite. Cem Concr Res 2000;30:1641-6. doi:10.1016/S00088846(00)00331-8.

[16] Snellings R, Mertens G, Elsen J. Calorimetric evolution of the early pozzolanic reaction of natural zeolites. J Therm Anal Calorim 2009;101:97-105. doi:10.1007/s10973-009-0449-x.

[17] Kosanovic C, Cizmek A, Subotic B, Smit I, Stubicar M, Tonejc A. Mechanochemistry of zeolites : Part 3 . Amorphization of zeolite ZSM- 5 by ball milling. Zeolites 1995;15:51-7.

[18] Kosanovic C, Cizmek A, Subotic B, Smit I, Stubicar M, Tonejc A. Mechanochemistry of zeolites . Part $4:$ Influence of cations on the rate of amorphization of zeolite A by ball milling. Zeolites 1995;15:632-6.

[19] Johnson M, O'Connor D, Barnes P, Catlow CR a., Owens SL, Sankar G, et al. Cation Exchange, Dehydration, and Calcination in Clinoptilolite: In Situ X-ray Diffraction and Computer Modeling. J Phys Chem B 2003;107:942-51. doi:10.1021/jp021672+. 
[20] Ates A, Hardacre C. The effect of various treatment conditions on natural zeolites: ion exchange, acidic, thermal and steam treatments. J Colloid Interface Sci 2012;372:130-40. doi:10.1016/j.jcis.2012.01.017.

[21] Duvarcı ÖÇ, Akdeniz Y, Özmıhçı F, Ülkü S, Balköse D, Çiftçioğlu M. Thermal behaviour of a zeolitic tuff. Ceram Int 2007;33:795-801. doi:10.1016/j.ceramint.2006.01.003.

[22] Fernández R, Vigil de la Villa R, Garcia R, Rodriguez O, Frias M, Villar-Cociña E. Characterization and pozzolanic activity of a calcined natural zeolite. 13th Int. Congr. Chem. Cem., 2011, p. 1-7.

[23] ASTM C150: Standard Specification for Portland Cement. Am Soc Test Mater 2012:1-9. doi:10.1520/C0150.

[24] ASTM C109: Standard Test Method for Compressive Strength of Hydraulic Cement Mortars (Using 2-in. or [50-mm] Cube Specimens). Am Soc Test Mater 2011:1-9. doi:10.1520/C0109.

[25] ASTM C778 - Standard Specification for Sand. Am Soc Test Mater 2014:21-3. doi:10.1520/C0778-13.2.

[26] Reynolds, Jr. R. Principles of Powder Diffraction. In: Bish DL, Post JE, editors. Mod. Powder Diffr. Vol. 20, Washington, D.C.: Mineralogical Society of America; 1989.

[27] Bergerhoff G, Brown ID. Crystallographic Databases. Int Union Crystallogr 1987;F.H. Allen.

[28] Downs RT, Hall-Wallace M. The American Mineralogist crystal structure database. Am Mineral 2003;88:247-50.

[29] McCarthy GJ, Johansen DM, Steinward SJ, Thedchanamoorthy A. X-ray diffraction analysis of fly ash. Adv X-Ray Anal 1988:331-42.

[30] Brunauer S, Emmett PH, Teller E. Adsorption of Gases in Multimolecular Layers. J Am Chem Soc 1938;60:309-19.

[31] Barrett EP, Joyner LG, Halenda PP. The determination of pore volume and area distributions in porous substances. I. Computations from nitrogen isotherms. J Am Chem Soc 1951;73:373-80.

[32] Ramachandran VS. Thermal Analysis. In: Ramachandran VS, Beaudoin JJ, editors. Handb. Anal. Tech. Concr. Sci. Technol., Norwich, New York: 2001, p. 990. 
555

[33] Moosberg-Bustnes H, Lagerblad B, Forssberg E. The function of fillers in concrete. Mater Struct 2004;37:74-81.

[34] ASTM C305: Standard Practice for Mechanical Mixing of Hydraulic Cement Pastes and Mortars. Am Soc Test Mater 2011:13-5. doi:10.1520/C0305-11.2.

[35] ASTM C1679: Standard Practice for Measuring Hydration Kinetics of Hydraulic Cementitious Mixtures Using Isothermal Calorimetry. Am Soc Test Mater 2009:114.

[36] Bullard JW, Jennings HM, Livingston R a., Nonat A, Scherer GW, Schweitzer JS, et al. Mechanisms of cement hydration. Cem Concr Res 2011;41:1208-23. doi:10.1016/j.cemconres.2010.09.011.

[37] Thomas JJ, Jennings HM, Chen JJ, Quentin S, Falla V. Influence of Nucleation Seeding on the Hydration Mechanisms of Tricalcium Silicate and Cement. J Phys Chem C 2009;113:4327-34.

[38] Cheung J, Jeknavorian a., Roberts L, Silva D. Impact of admixtures on the hydration kinetics of Portland cement. Cem Concr Res 2011;41:1289-309. doi:10.1016/j.cemconres.2011.03.005.

[39] Lothenbach B, Scrivener K, Hooton RD. Supplementary cementitious materials. Cem Concr Res 2011;41:1244-56. doi:10.1016/j.cemconres.2010.12.001.

[40] Roszczynialski W. DETERMINATION OF POZZOLANIC ACTIVITY OF MATERIALS BY THERMAL ANALYSIS. J Therm Anal Calorim 2002;70:38792.

[41] Wild S, Khatib JM. Portlandite Consumption in Metakaolin Cement Pastes and Mortars. Cem Concr Res 1997;27:137-46.

[42] Antoni M, Rossen J, Martirena F, Scrivener K. Cement substitution by a combination of metakaolin and limestone. Cem Concr Res 2012;42:1579-89. doi:10.1016/j.cemconres.2012.09.006.

[43] Snellings R, Mertens G, Cizer Ö, Elsen J. Early age hydration and pozzolanic reaction in natural zeolite blended cements: Reaction kinetics and products by in situ synchrotron X-ray powder diffraction. Cem Concr Res 2010;40:1704-13. doi:10.1016/j.cemconres.2010.08.012.

[44] Oey T, Kumar A, Bullard JW, Neithalath N, Sant G. The Filler Effect: The Influence of Filler Content and Surface Area on Cementitious Reaction Rates. J Am Ceram Soc 2013;96:1978-90. doi:10.1111/jace.12264. 
588 [45] Rahhal V, Talero R. Early hydration of portland cement with crystalline mineral additions. Cem Concr Res 2005;35:1285-91. doi:10.1016/j.cemconres.2004.12.001.

591 [46] Jankovic A, Valery W, Davis E. Cement grinding optimisation. Miner Eng 2004;17:1075-81. doi:10.1016/j.mineng.2004.06.031. 
Black and white figures for printed paper version.

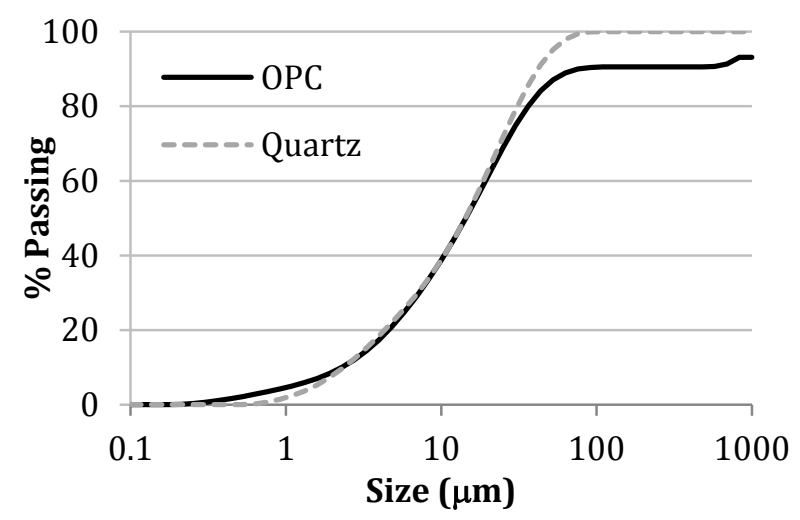

Figure 1 - Particle size distributions of OPC and quartz filler.

600

601
602

603

604

605

606

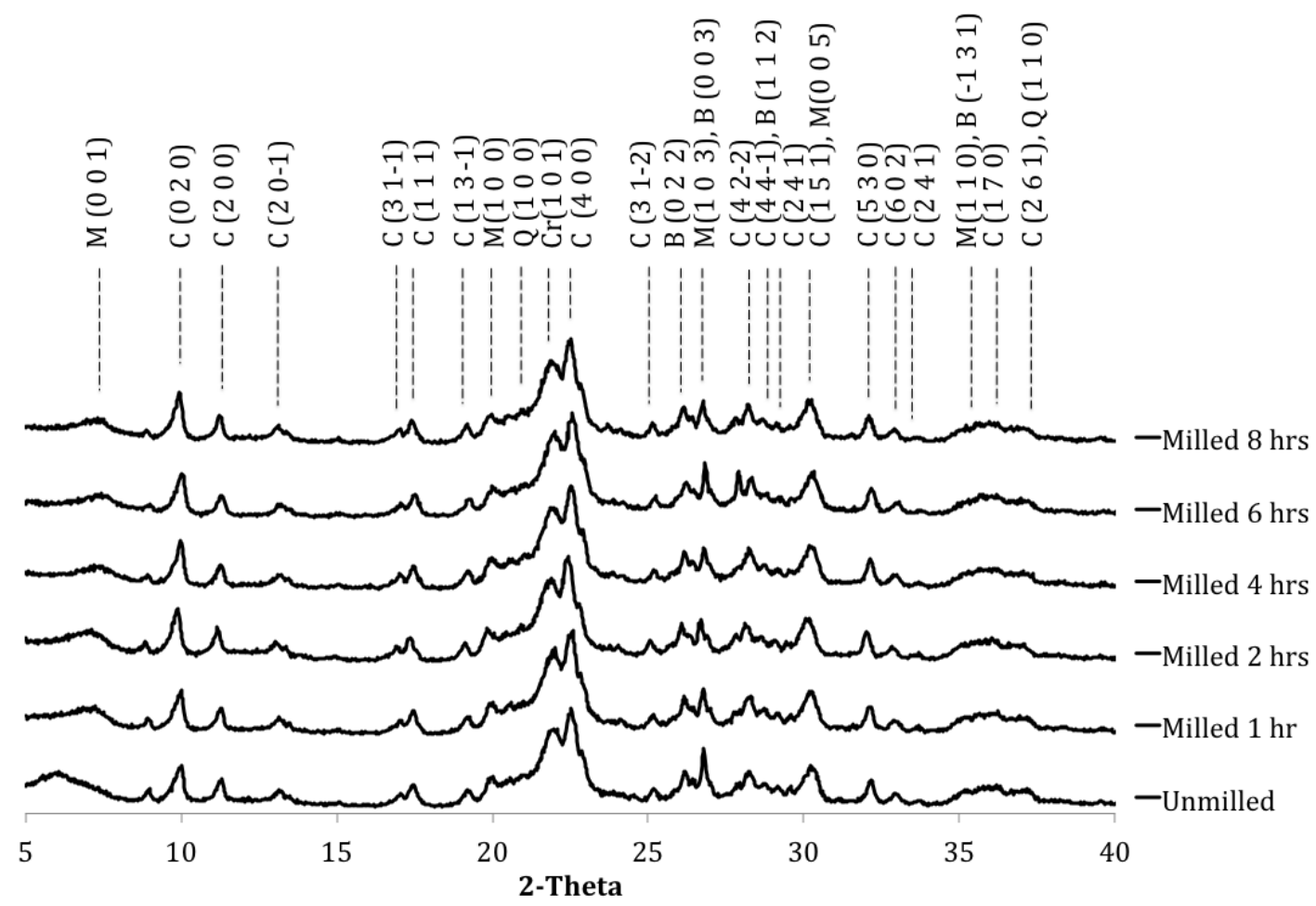

Figure 2 - Crystalline phases in the zeolite sample before and after milling. $\mathrm{C}=$ clinoptilolite zeolite $\left((\mathrm{Na}, \mathrm{K}, \mathrm{Ca})_{2-3} \mathrm{Al}_{3}(\mathrm{Al}, \mathrm{Si})_{2} \mathrm{Si}_{13} \mathrm{O} \cdot \mathbf{1 2}_{2} \mathrm{O}\right), \mathrm{Cr}=$ cristobalite $\left(\mathrm{SiO}_{2}\right), \mathrm{M}=$ montmorillonite

$\left((\mathrm{Na}, \mathrm{Ca})_{0.33}(\mathrm{Al}, \mathrm{Mg})_{2}\left(\mathrm{Si}_{4} \mathrm{O}_{10}\right)(\mathrm{OH})_{2} \cdot \mathrm{nH}_{2} \mathrm{O}\right) \mathrm{Q}=$ quartz $\left(\mathrm{SiO}_{2}\right)$. Numbers in parenthesis indicate the d-spacing of the reflection.

607 


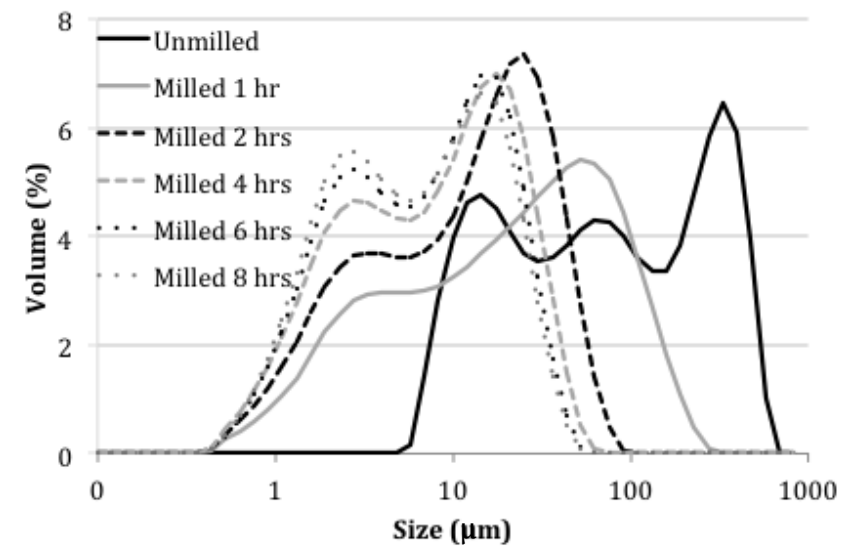

608

Figure 3 - Volumetric particle size distribution of unmilled and milled zeolite.

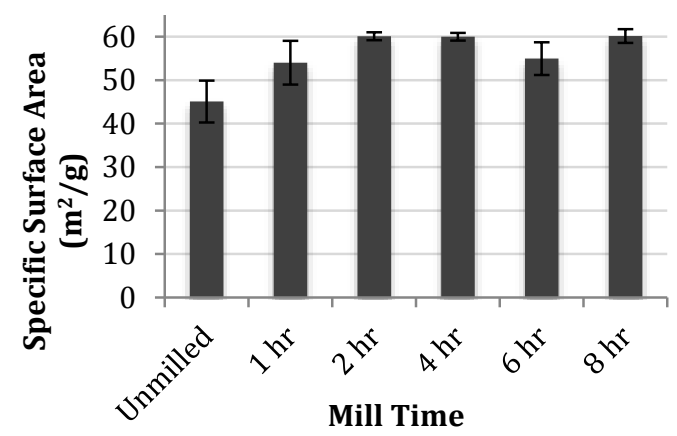

611 Figure 4 - Nitrogen available surface area of the unmilled and milled zeolite.

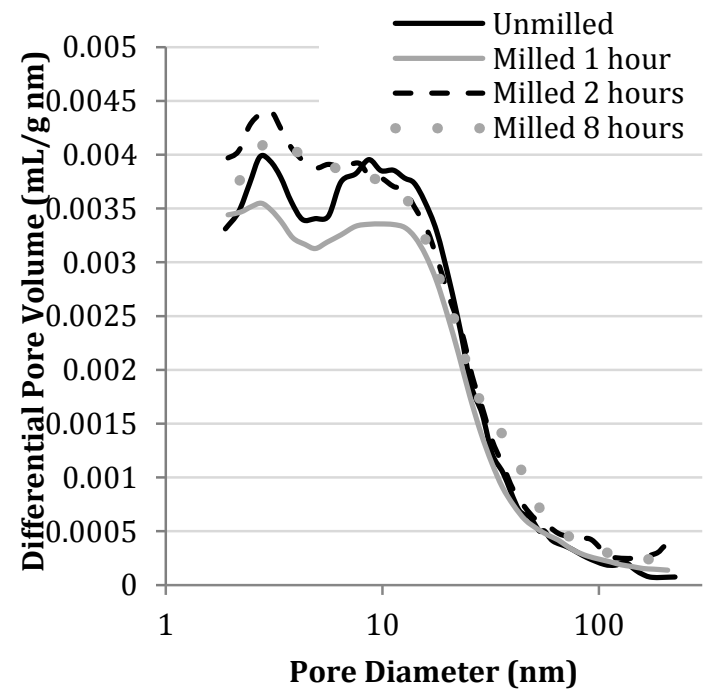

612

613 Figure 5 - Pore size distribution of unmilled and milled zeolite. 


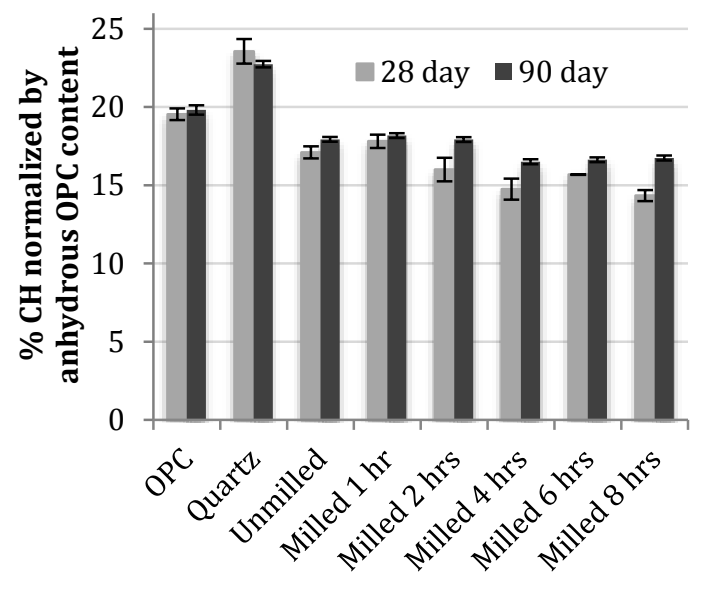

614

615 Figure 6 - Calcium hydroxide (CH) content by weight of hydrated cement pastes containing $80-100 \%$ 616 OPC and $0-20 \%$ unmilled or milled zeolite or quartz filler $(\mathrm{w} / \mathrm{cm}=0.4)$.

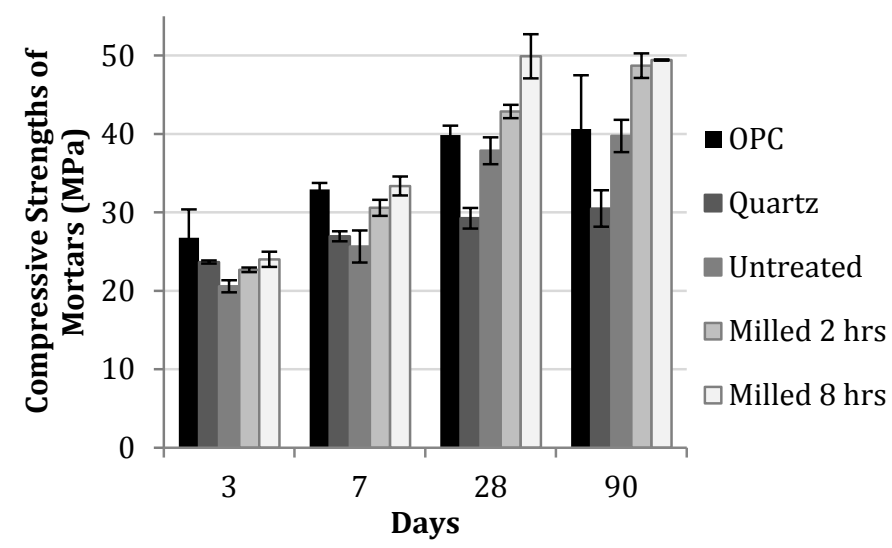

618 Figure 7 - Compressive strengths of cement mortars containing $80-100 \%$ cement and $0-20 \%$ of unmilled 619 zeolite, milled zeolite, or a quartz filler $(\mathrm{w} / \mathrm{cm}=0.51)$. 


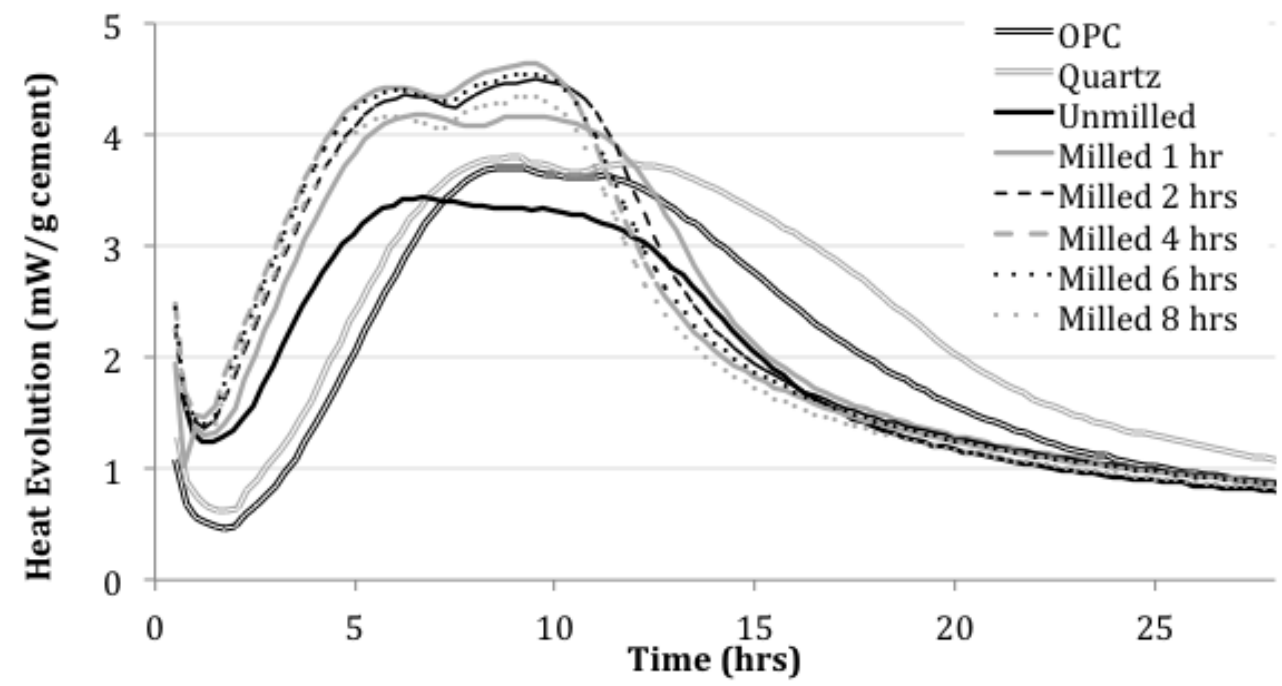

Figure 8 - Isothermal calorimetry $\left(23^{\circ} \mathrm{C}\right)$ results of pastes with $80-100 \%$ cement and $0-20 \%$ unmilled 625 zeolite, milled zeolite, or quartz filler $(\mathrm{w} / \mathrm{cm}=0.4)$.

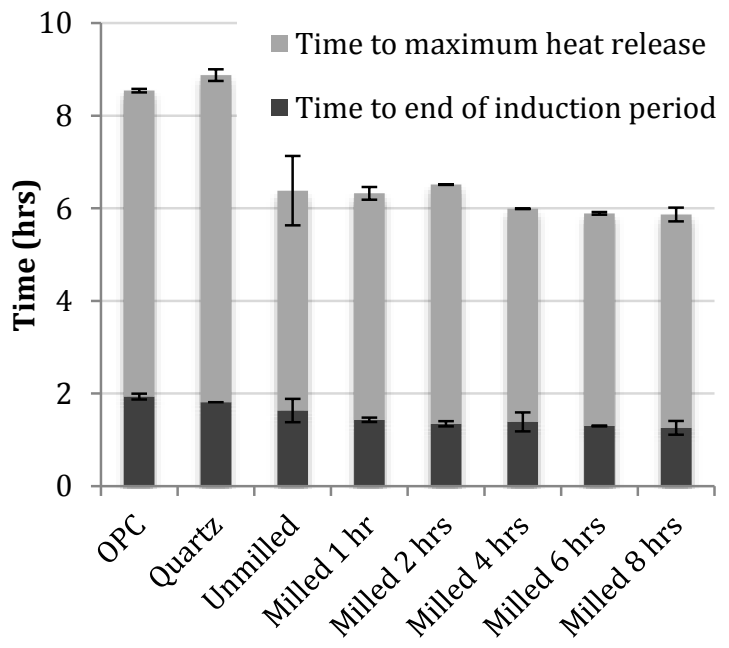

Figure 9 - Time to the end of the induction period and time to the maximum value of heat flow in 628 isothermal calorimetry $\left(23^{\circ} \mathrm{C}\right)$ of pastes with $80-100 \%$ cement and $0-20 \%$ unmilled or milled zeolite $629(\mathrm{w} / \mathrm{cm}=0.4)$. 


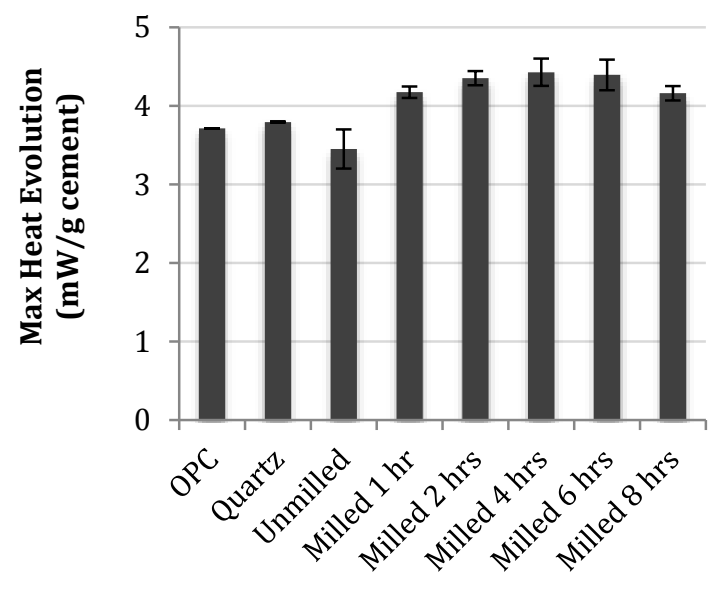

630

631 Figure 10 - Value of the maximum heat flow in isothermal calorimetry $\left(23^{\circ} \mathrm{C}\right)$ of pastes with $80-100 \%$ 632 cement and $0-20 \%$ unmilled or milled zeolite $(\mathrm{w} / \mathrm{cm}=0.4)$.

633

634

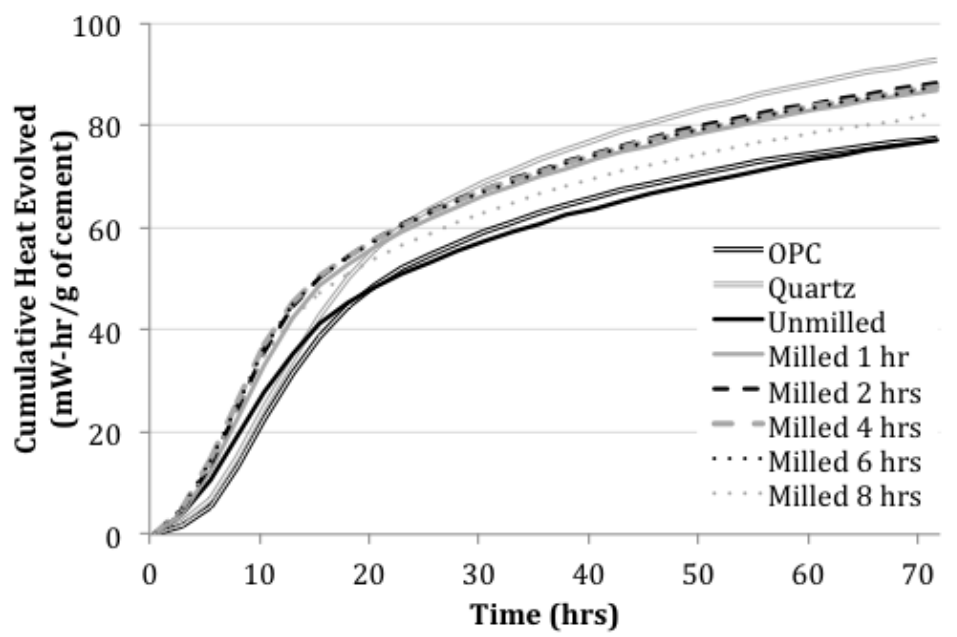

636 Figure 11 - Cumulative heat over 72 hours during isothermal calorimetry $\left(23^{\circ} \mathrm{C}\right)$ of $80-100 \%$ cement and $0-20 \%$ unmilled zeolite, milled zeolite, or quartz filler pastes $(\mathrm{w} / \mathrm{cm}=0.4)$. 
Table 1 - Oxide compositions (mass \%) of the natural zeolite and cement determined using XRF.

\begin{tabular}{|c|c|c|}
\hline Oxide & Zeolite & OPC \\
\hline $\mathrm{SiO}_{2}$ & 62.23 & 19.36 \\
\hline $\mathrm{Al}_{2} \mathrm{O}_{3}$ & 11.88 & 5.13 \\
\hline $\mathrm{Fe}_{2} \mathrm{O}_{3}$ & 1.12 & 2.53 \\
\hline $\mathrm{CaO}$ & 2.21 & 63.17 \\
\hline $\mathrm{MgO}$ & 0.64 & 1.03 \\
\hline $\mathrm{SO}_{3}$ & - & 3.22 \\
\hline $\mathrm{Na}_{2} \mathrm{O}$ & 1.00 & 0.09 \\
\hline $\mathrm{K}_{2} \mathrm{O}$ & 1.68 & 0.88 \\
\hline
\end{tabular}

640

641

642

643

644

645

Table 3 - Acceleration period slope in isothermal calorimetry $\left(23^{\circ} \mathrm{C}\right)$ of pastes with $80-100 \%$ cement and
$0-20 \%$ unmilled zeolite, milled zeolite, or quartz filler $(\mathrm{w} / \mathrm{cm}=0.4)$.

\begin{tabular}{|c|c|}
\hline SCM/filler & $\begin{array}{c}\text { Acceleration Period Slope } \\
(\mathrm{mW} / \mathrm{g} / \mathrm{hr})\end{array}$ \\
\hline None & $0.66 \pm 0.05$ \\
\hline Quartz & $0.64 \pm 0.03$ \\
\hline Unmilled zeolite & $0.60 \pm 0.11$ \\
\hline Milled 1 hr zeolite & $0.76 \pm 0.06$ \\
\hline Milled 2 hrs zeolite & $0.77 \pm 0.10$ \\
\hline Milled 4 hrs zeolite & $0.83 \pm 0.08$ \\
\hline Milled 6 hrs zeolite & $0.85 \pm 0.12$ \\
\hline Milled 8 hrs zeolite & $0.83 \pm 0.07$ \\
\hline
\end{tabular}

Table 2 - Summary of zeolite particle size distributions before and after milling

\begin{tabular}{|c|c|c|c|}
\hline \multirow{2}{*}{$\begin{array}{c}\text { Mill Time } \\
(\mathbf{h r s})\end{array}$} & \multicolumn{3}{|c|}{ Particle Sizes $(\boldsymbol{\mu m})$} \\
\cline { 2 - 4 } & $\mathbf{d}_{\mathbf{1 0}}$ & $\mathbf{d}_{\mathbf{5 0}}$ & $\mathbf{d}_{\mathbf{9 0}}$ \\
\hline Unmilled & 12.8 & 77.4 & 408.6 \\
\hline 1 & 2.6 & 25.1 & 111.7 \\
\hline 2 & 2.0 & 13.9 & 42.3 \\
\hline 4 & 1.7 & 9.0 & 29.5 \\
\hline 6 & 1.7 & 7.8 & 25.7 \\
\hline 8 & 1.6 & 6.9 & 24.3 \\
\hline
\end{tabular}

646

647 